\section{Galileo would have loved sports biomechanics, digitised ECG and his smartphone}

\author{
Ben Clarsen, ${ }^{1,2}$ Hilde Moseby Berge ${ }^{1,3}$
}

Galileo Galilei (1564-1642) is often referred to as the father of modern science. Initially a medical student, his obsession with measurement soon turned him to physics, mathematics and astronomy. Galileo was the first to accurately measure time by harnessing the principles of the pendulum and his improvements of the telescope led to massive advances in the fields of physics and astronomy. In particular, he provided the first empirical evidence that the earth revolved around the sun, and not vice versa. The 17th century's 'Steve Jobs' figure, Galileo invented the microscope, thermometer and compass. Just as Jobs revolutionised our thinking towards mobile computing by promising 'a thousand songs in your pocket', Galileo rocked his world by saying 'measure all that is measurable, and make measurable what is not.'

Is our digital revolution going be considered another 'golden age'? For sports clinicians and scientists, technological advances are opening up possibilities we could previously only dream of, particularly when it comes to measuring what was previously immeasurable. Our brilliant issue cover depicts new measurement possibilities in sports medicine. This picture illustrates how Gilgien et al (see page 742) turned the world's best ski slopes into biomechanics laboratories by harnessing satellite positioning and digital terrain modelling technology. As discussed by Bere and Bahr (see page 738 ), linking this innovative approach to existing injury surveillance may be an important step towards prevention of skiing injuries. Simulation of reallife game situations in the laboratory is another creative biomechanical approach featured in this edition, with Kristianslund

${ }^{1}$ Oslo Sports Trauma Research Center, Norwegian School of Sport Sciences, Oslo, Norway; ${ }^{2}$ Sports Physiotherapy Group, Norwegian Physiotherapy Association (FFI); ${ }^{3}$ The Norwegian Association of Sports Medicine and Physical Activity (NIMF)

Correspondence to Ben Clarsen, Oslo Sports Trauma Research Center, Norwegian School of Sports Sciences, PO Box 4014 Ullevål Stadion, Oslo 0806, Norway; ben.clarsen@nih.no et al (see page 779) making detailed calculations of side-step cutting in handball.

Nowadays it is not just songs in your pocket, but a virtual sports medicine clinic and performance lab in there too. Smartphones are powerful tools for collecting and communicating information, and according to Verhagen et al (see page 739), electronic-health (eHealth) is the future of sports medicine. A good example of this is provided by Grindem et al (see page 748), who show how online reporting of sports participation can be used to track patients' return to sport after an anterior cruciate ligament injury. Similarly, Clarsen et al (see page 754) describe how an Internet questionnaire can help to optimise the health of Norway's Olympic athletes. Both these papers describe methods that would have been logistically impossible prior to the digital revolution. The same might be said about the study by Bjørneboe et al (see page 774), who use video analysis to make important recommendations about injury prevention in football.

Also in sports cardiology, computer measurements of ECG are taking over from the traditional 'ruler-on-paper' approach. However, as Berge et al demonstrate (see page 761), the prevalence of abnormal ECG findings in athletes differs significantly depending on the measurement methods used.

New measurement technology will probably fascinate some and irritate others. We are sure though, that as new methods prove their scientific and practical value, they will be appreciated by the sports medicine world. Galileo, on the other hand, met so much resistance to his indications that the earth revolved around the sun that he was sentenced to life imprisonment and died after 9 years in house arrest. Today his revolutionary measurements are accepted as fact.

\section{ALSO IN THIS ISSUE}

This year's 'Norwegian' edition of BJSM would not be complete without a paper investigating the health benefits of physical activity. In a large randomised controlled trial targeting school children,
Grydeland et al (see page 768) measured positive effects, but only in some groups. You may remember that the implications of this important study was discussed by Sigmund Alfred Anderssen in last year's edition. ${ }^{1}$

In this issue we also pay particular attention to degenerative meniscus injuries, a common condition in primary-care sports medicine. In her editorial, Risberg (see page 741), argues strongly that exercise, not surgery, should be the first-line treatment for these patients. She also highlights how the cross-sectional study by Stensrud et al (see page 784) fills an important knowledge-gap in the field.

\section{BUILDING A STRONG INTERNATIONAL NETWORK THROUGH BJSM}

We have just returned from IOC's World Conference on Prevention of Injury \& Illness in Sport in Monaco, where we had the pleasure to meet many of you and listen to lots of brilliant presentations. Thank you! Special thanks also to BJSM for organising a meeting in Monaco for their member societies. It was fantastic to learn from the experience of our international colleagues, and we return full of inspiration and new ideas about how our societies can continue to develop sports medicine and sports physiotherapy in Norway. As a BJSM reader, you can look forward to the results of our creative workshops in Monaco.

On behalf of the Norwegian Association of Sports Medicine and Physical Activity (NIMF) and the Sports Physiotherapy Group of the Norwegian Physiotherapy Association (FFI), we hope you enjoy this edition of BJSM!

Contributors $B C$ and $\mathrm{HMB}$ contributed to planning and writing this manuscript.

Competing interests None.

Provenance and peer review Not commissioned; internally peer reviewed.

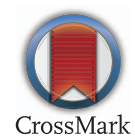

To cite Clarsen B, Moseby Berge H. Br J Sports Med 2014;48:737.

Accepted 24 February 2014

Br J Sports Med 2014;48:737.

doi:10.1136/bjsports-2014-093588

\section{REFERENCE}

1 Anderssen SA. Promoting healthy weight in school children: what does the HEIA study teach us about effective interventions? Br I Sports Med 2013:47:469. 